\title{
Comparison of sliding mode controller application for buck- boost converter based on linear sliding surface
}

\author{
Lunde Ardhenta, Tri Nurwati \\ Department of Electrical Engineering, Universitas Brawijaya, Malang, Indonesia
}

\begin{tabular}{l}
\hline \hline Article Info \\
\hline Article history: \\
Received Jul 30, 2021 \\
Revised Jan 24, 2022 \\
Accepted Jan 31, 2022 \\
\hline
\end{tabular}

Keywords:

Buck-boost converter Linear sliding surface Proportional integral derivative Integral of time-weighted absolute error Sliding-mode control

\begin{abstract}
In the utilization of photovoltaic (PV), the output voltage produced is unstable because the conditions of irradiation received by PV is not uniform. Therefore, a direct current (DC) voltage converter is needed as an output voltage regulator. In this research, buck-boost converter is proposed to regulate the desired output voltage. The proposed controller in this research is a sliding mode controller (SMC) and employ a linear sliding surface to maintain the regulated voltage stable. This research was conducted by determining the component parameters and state space model of the buckboost converter. Proportional integral derivative (PID) controller with integral of time-weighted absolute error (ITAE) method is used as a comparison of the proposed method. The performance results were observed from the buck-boost converter by performing 3 fault scenarios, variation in supply voltage, resistor in load side, and the desired output voltage. The results obtained of SMC has a faster settling time than PID controller. The voltage deviation of buck-boost converter exhibits that SMC is smaller than the PID control. In addition, under some experiment conditions, the PID control could not or did not fit in some scenarios while the output control values of SMC matched the changes in the entire scenarios.
\end{abstract}

This is an open access article under the CC BY-SA license.

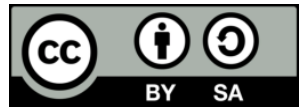

\section{Corresponding Author:}

Lunde Ardhenta

Department of Electrical Engineering, Universitas Brawijaya

MT Haryono St. 167 Malang, Indonesia

Email: lunde.ardhenta@ub.ac.id

\section{INTRODUCTION}

Utilization of renewable energy resources (RER) to be converted into electrical energy is currently growing rapidly. This is due to the increasing demand for electricity but the supply of fossil energy is decreasing. The potential resource is currently being widely applied is solar cells or photovoltaic (PV) [1]. $\mathrm{PV}$ is a device or component that works based on the photoelectric effect on a semiconductor material to convert light energy into electrical energy [2]. However, one of the obstacles in the utilization of PV is the unstable generated voltage. This is because the voltage generated depends on the condition of the intensity of sunlight received by the PV at all times. Whereas in general, electronic devices have specification limits for voltage variations, frequency variations, and harmonic distortion [3]. If the unstable voltage output continues to be ignored, it will result in less than optimal usage and can accelerate damage to electronic equipment. Most of the electricity generated by RER, such as PV, is direct current (DC) voltage. In order to accomplish this problem, developing a DC-DC converter to stabilize the regulated voltage is most important [4]. There are several types of basic converter that have different capabilities which are step-down converter (buck converter), step-up converter (boost converter), and buck-boost converter.

Buck-boost converter is DC voltage converter whose regulated voltage is invert value and is able to be set higher or lower than the supply voltage by using pulse width modulation (PWM). Currently, buck- 
boost converter is commonly employed in various applications such as photovoltaic systems, fuel-cells, electric vehicles, and uninterrupted power supplies [5]-[10]. The difficulty in regulating the voltage for buckboost converter is caused by the non-minimum phase structure in mathematical model. Inductor current regulation can indirectly adjust the generated voltage of DC converter. This converter is included in nonlinear system and performs in the time domain, such that the conventional linear adjustment technique is not suitable to be applied in controlling this converter. The suitable control technique for converters must overcome the intrinsic nonlinearity, variations in some disturbances, and confirm the stability under some operating conditions by observing the transient response [11]-[13].

Currently, there are various kinds of controls, one of which is the proportional-integral-derivative (PID) controller. According to a survey among tens of thousands of controller types, most controllers employed for regulatory purposes in the chemical, paper, and refining factories is PID controller [14]. In order to compensate the deviation or error between desired value and feedback value, applications of PID controller in power converter are widely used due to the effectiveness and the easiness [15]-[19]. Mostly PID controllers are effective when the system is linear, however these conventional PIDs are not able to compensate the response from non-linear systems or high-order systems [19]. Therefore, a suitable controller is required for a non-linear system as in buck-boost converter. Sliding mode controllers (SMC) are renowned for their durability and stability. This controller is a nonlinear control approaching that is suitable with the nonlinear characteristics of DC-DC converter especially buck-boost converter [11]. SMC has a simple implementation and it is quite resistant to interference. By using this sliding mode control method, it will process mathematical equations by reducing low frequency components which will suppress ripple variations due to imperfect switching processes [20].

The utilization of SMC with linear sliding surface and PID control with integral of time-weighted absolute error (ITAE) method in buck-boost converter are conducted in this research. The calculation of proposed method is carried out by employing state-space model as as approaching plant model. The verification of the proposed controller is performed by changing the supply voltage, resistor in load side, and the desired output voltage. The proposed controller is intended to keep the generated voltage of the buckboost converter as desired voltage.

\section{THE PROPOSED METHOD}

The proposed method is the application of a sliding mode controller to a buck-boost converter which is employed to improve the settling time. The application of a simple linear sliding surface is carried out. The proposed combination of sliding surface is compiled using inductor current and output voltage.

\subsection{Buck-boost converter}

The circuit of buck-boost converter is displayed in Figure 1, it is composed of two passive components and two electronic switches (MOSFET and diode) [21]. The dynamic model of this converter describes the characteristics of a system which is defined from two states, a closed switch (ON) and an open switch (OFF). The current passes via the source, inductor, and electronic switch when ON state and there is no current through the load resistor and capacitor [22]. Figure 1 (a) depicts the closed switch of buck-boost converter. By analyzing the voltage and the current based on Kirchhoff's law (KL), the following equation is obtained:

$$
\begin{aligned}
& V s=L \frac{d_{i L}}{d t} \\
& C \frac{d V c}{d t}=-\frac{V_{c}}{R}
\end{aligned}
$$

If the (1) and (2) are moved, then the (3) and (4) can be obtained.

$\frac{\mathrm{d}_{\mathrm{iL}}}{\mathrm{dt}}=\frac{\mathrm{V}_{\mathrm{S}}}{\mathrm{L}}$

$\frac{\mathrm{dVc}}{\mathrm{dt}}=-\frac{\mathrm{V}_{\mathrm{c}}}{\mathrm{CR}}$

From (3) and (4) with $\mathrm{x}_{1}=\mathrm{i}_{\mathrm{L}}$ and $\mathrm{x}_{2}=\mathrm{v}_{\mathrm{C}}$, the equation below will be obtained:

$$
\begin{aligned}
& \mathrm{x}_{1}^{\prime}=\frac{1}{\mathrm{~L}} \mathrm{~V}_{\mathrm{s}} \\
& \mathrm{x}_{2}^{\prime}=-\frac{\mathrm{x}_{2}}{\mathrm{RC}}
\end{aligned}
$$


So, the matrix of state space in first state is:

$$
\left[\begin{array}{l}
\dot{\mathrm{x}}_{1} \\
\dot{\mathrm{x}}_{2}
\end{array}\right]=\left[\begin{array}{cc}
0 & 0 \\
0 & -\frac{1}{\mathrm{RC}}
\end{array}\right]\left[\begin{array}{l}
\mathrm{X}_{1} \\
\mathrm{x}_{2}
\end{array}\right]+\left[\begin{array}{c}
\frac{1}{\mathrm{~L}} \\
0
\end{array}\right] \mathrm{V}_{\mathrm{s}}
$$

In the second status Figure 1 (b), the current in inductor through the capacitor and load resistor because the diode is conducted. In this time, the inductor become voltage source in the circuit. The analysis is carried out by giving the output voltage $V_{o}$ with a constant value [22]. The (8) and (9) are derived by considering the voltage in capacitor and the inductor current using KL.

$$
\begin{aligned}
& -V c=-L \frac{d_{i L}}{d t} \\
& -i_{L}=C \frac{d V_{c}}{d t}+\frac{V_{c}}{R}
\end{aligned}
$$

If the (8) and (9) are moved, then the following equation can be obtained:

$$
\begin{aligned}
& \frac{\mathrm{d}_{\mathrm{iL}}}{\mathrm{dt}}=\frac{\mathrm{V}_{\mathrm{C}}}{\mathrm{L}} \\
& \frac{\mathrm{dV}_{\mathrm{c}}}{\mathrm{dt}}=-\frac{\mathrm{i}_{\mathrm{L}}}{\mathrm{C}}-\frac{\mathrm{V}_{\mathrm{C}}}{\mathrm{RC}}
\end{aligned}
$$

From (10) and (11) with $\mathrm{x}_{1}=\mathrm{i}_{\mathrm{L}}$ and $\mathrm{x}_{2}=\mathrm{v}_{\mathrm{C}}$, the equation below will be obtained:

$$
\begin{aligned}
& \dot{\mathrm{x}}_{1}=\frac{1}{\mathrm{~L}} \mathrm{x}_{2} \\
& \dot{\mathrm{x}}_{2}=-\frac{1}{\mathrm{C}} \mathrm{x}_{1}-\frac{1}{\mathrm{RC}} \mathrm{x}_{2}
\end{aligned}
$$

The state space matrix when the switch is opened is:

$$
\left[\begin{array}{l}
\dot{\mathrm{x}}_{1} \\
\dot{\mathrm{x}}_{2}
\end{array}\right]=\left[\begin{array}{cc}
0 & \frac{1}{\mathrm{~L}} \\
-\frac{1}{\mathrm{C}} & -\frac{1}{\mathrm{RC}}
\end{array}\right]\left[\begin{array}{l}
\mathrm{x}_{1} \\
\mathrm{x}_{2}
\end{array}\right]+\left[\begin{array}{l}
0 \\
0
\end{array}\right] \mathrm{V}_{\mathrm{s}}
$$

This state space equation when the opened switch is the same as the buck converter when the switch is opened [22]. The state space averaging (SSA) is determined by deriving the state of PWM during the switch is opened and closed as described in,

$$
\begin{aligned}
& \bar{A}=A_{(\text {on })} d+A_{(\text {off })}(1-d) \\
& \bar{A}=\left[\begin{array}{cc}
0 & 0 \\
0 & -\frac{1}{R C}
\end{array}\right] d+\left[\begin{array}{cc}
0 & \frac{1}{L} \\
-\frac{1}{C} & -\frac{1}{R C}
\end{array}\right](1-d)=\left[\begin{array}{cc}
0 & \frac{1-d}{L} \\
-\frac{1-d}{C} & -\frac{1}{R C}
\end{array}\right] \\
& \bar{B}=B_{(\text {on })} d+B_{(\text {off })}(1-d) \\
& \bar{B}=\left[\begin{array}{l}
\frac{1}{L} \\
0
\end{array}\right] d+\left[\begin{array}{l}
0 \\
0
\end{array}\right](1-d)=\left[\begin{array}{l}
\frac{d}{L} \\
0
\end{array}\right]
\end{aligned}
$$

By substituting the (15) and (16), the complete buck-boost converter model is defined as (17).

$$
\left[\begin{array}{l}
\dot{\mathrm{X}}_{1} \\
\dot{\mathrm{X}}_{2}
\end{array}\right]=\left[\begin{array}{cc}
0 & \frac{1-\mathrm{d}}{\mathrm{L}} \\
-\frac{1-\mathrm{d}}{\mathrm{C}} & -\frac{1}{\mathrm{RC}}
\end{array}\right]\left[\begin{array}{l}
\mathrm{X}_{1} \\
\mathrm{x}_{2}
\end{array}\right]+\left[\begin{array}{l}
\frac{\mathrm{d}}{\mathrm{L}} \\
0
\end{array}\right] \mathrm{V}_{\mathrm{S}}
$$

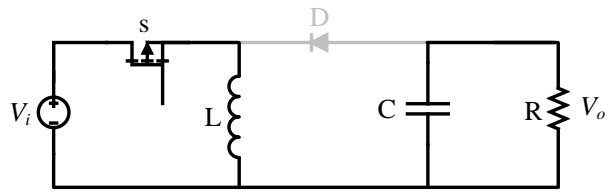

(a)

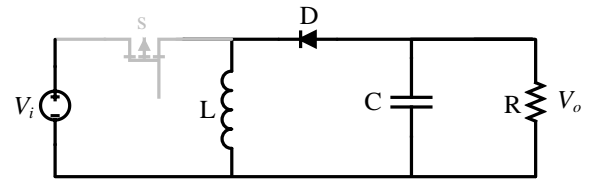

(b)

Figure 1. Buck-boost converter circuit (a) in ON state and (b) in OFF state 


\subsection{Sliding mode control design}

The appropriate output voltage is regulated based on suitable parameter of SMC. The calculation of this parameter begins by determining the parameters to be used as an error equation or sliding surface equation [23]. In this study, the reference used is capacitor voltage and inductor current, so the sliding surface equation used is in accordance with (18).

$$
\mathrm{S}(\mathrm{x})=\alpha_{1}\left(\mathrm{x}_{1}-\mathrm{i}^{*}\right)+\alpha_{2}\left(\mathrm{x}_{2}-\mathrm{v}^{*}\right)
$$

Where, $\alpha_{1}$ and $\alpha_{2}$ are sliding coefficients or parameters of the sliding surface, $\mathrm{x}_{1}$ represents of the current via the inductor, $\mathrm{x}_{2}$ is the output voltage of the buck-boost converter, $\mathrm{i}^{*}$ is the desired current, and $\mathrm{v}^{*}$ is the reference voltage. Determination of the duty cycle in SMC is defined by two parameters, $U_{\text {eq }}$ and $U_{n}$ which is shown in (19) [24], [25].

$$
\mathrm{U}=\mathrm{U}_{\mathrm{eq}}+\mathrm{U}_{\mathrm{n}}
$$

The $\mathrm{U}_{\mathrm{eq}}$ or continuous equivalent controller is obtained by calculating the first derivative of $\mathrm{S}(\mathrm{x})$ which is equated to zero. By substituting the equations $\dot{\mathrm{x}}_{1}$ and $\dot{\mathrm{x}}_{2}$ to derivative of $\mathrm{S}(\mathrm{x})$, the state space averaging buck-boost converter, becomes:

$$
\alpha_{1}\left(\frac{1-\mathrm{d}}{\mathrm{L}} \mathrm{x}_{2}+\frac{\mathrm{d}}{\mathrm{L}} \mathrm{V}_{\text {in }}\right)+\alpha_{2}\left(-\frac{(1-\mathrm{d})}{\mathrm{C}} \mathrm{x}_{1}-\frac{\mathrm{x}_{2}}{\mathrm{RC}}\right)=0
$$

The next step is to collect terms containing variable $\mathrm{d}$ (duty cycle) on the left and move terms that do not contain variable $\mathrm{d}$ to the right side. Therefore, the equation $\mathrm{U}_{\mathrm{eq}}$ acquired is:

$$
\mathrm{U}_{\mathrm{eq}}=\frac{-\alpha_{1} R C \mathrm{x}_{2}+\alpha_{2} \mathrm{~L}\left(\mathrm{Rx}_{1}+\mathrm{x}_{2}\right)}{\alpha_{1} \mathrm{RC}\left(\mathrm{V}_{\mathrm{in}}-\mathrm{x}_{2}\right)+\alpha_{2} \mathrm{RLx}_{1}}
$$

Then the calculation of the duty cycle on SMC is continued by looking for the discontinuous normal controller $U_{n}$. The calculation of this $U_{n}$ is based on Lyapunov function as a stability investigation.

$$
\mathrm{V}=\frac{1}{2} \mathrm{~S}(\mathrm{x})^{2}
$$

In order to satisfy that this plant have a stable system, the first derivative of the above equation must satisfy negative definite $(\dot{V}<0)$. The first derivative of the Lyapunov stability equation is:

$$
\dot{\mathrm{V}}=\mathrm{SS}
$$

By substituting $\dot{S}$ as the sliding surface in first derivation and control signal $\left(U_{\text {eq }}+U_{n}\right), U_{n}$ can be obtained and it can be shown in (24).

$$
\begin{aligned}
& \mathrm{U}_{\mathrm{n}}=-\alpha_{3} \cdot\left(\left(\frac{\alpha_{2} \mathrm{x}_{1}}{\mathrm{C}}+\frac{\alpha_{2} \mathrm{x}_{2}}{\mathrm{RC}}-\frac{\mathrm{k}_{1} \mathrm{x}_{2}}{\mathrm{~L}}-\frac{\alpha_{1}{ }^{2} \mathrm{Cx}_{2}\left(\mathrm{x}_{2}-\mathrm{V}_{\mathrm{in}}\right)}{\mathrm{L}\left(\alpha_{1} \mathrm{C}\left(\mathrm{V}_{\mathrm{in}}-\mathrm{x}_{2}\right)+\alpha_{2} \mathrm{Lx} \mathrm{x}_{1}\right)}+\frac{\alpha_{1} \alpha_{2}\left(\mathrm{Rx}_{1}+\mathrm{x}_{2}\right)\left(\mathrm{x}_{2}+\mathrm{V}_{\mathrm{in}}\right)}{\mathrm{R}\left(\alpha_{1} \mathrm{C}\left(\mathrm{V}_{\mathrm{in}}-\mathrm{x}_{2}\right)+\alpha_{2} \mathrm{Lx} \mathrm{x}_{1}\right)}+\right.\right. \\
& \left.\left.\frac{\alpha_{2} x_{1}\left(\alpha_{1} R C x_{2}+\alpha_{2} L\left(R_{1}+x_{2}\right)\right)}{\operatorname{RC}\left(\alpha_{1} R L C\left(V_{\text {in }}-x_{2}\right)+\alpha_{2} R L x_{1}\right)}\right):\left(\frac{\alpha_{1} C V_{i n}-\alpha_{1} x_{2} C+\alpha_{2} x_{1} L}{L C}\right)\right) \operatorname{sign}(S)
\end{aligned}
$$

Where, $\alpha$ is a positive sliding coefficient, in order to fulfill the negative definition of Lyapunov function as stability theory, and $\mathrm{S}$ is the sliding surface equation. The implemented signal control for the buck-boost converter $\mathrm{U}$ is derived by calculating the $\mathrm{U}_{\mathrm{eq}}$ and $\mathrm{U}_{\mathrm{n}}$ as written in (25).

$$
\begin{aligned}
& \mathrm{U}=\mathrm{U}_{\mathrm{eq}}+\mathrm{U}_{\mathrm{n}} \\
& \mathrm{U}=\left[\frac{-\alpha_{1} \mathrm{RCx}_{2}+\alpha_{2} \mathrm{~L}\left(\mathrm{Rx}_{1}+\mathrm{x}_{2}\right)}{\alpha_{1} \mathrm{RC}\left(\mathrm{V}_{\mathrm{in}}-\mathrm{x}_{2}\right)+\alpha_{2} \mathrm{RLx}_{1}}\right]+\left[-\alpha_{3} \cdot\left(\left(\frac{\alpha_{2} \mathrm{x}_{1}}{\mathrm{C}}+\frac{\alpha_{2} \mathrm{x}_{2}}{\mathrm{RC}}-\frac{\alpha_{1} \mathrm{x}_{2}}{\mathrm{~L}}-\frac{\alpha_{1}{ }^{2} \mathrm{Cx}_{2}\left(\mathrm{x}_{2}-\mathrm{V}_{\text {in }}\right)}{\mathrm{L}\left(\alpha_{1} \mathrm{C}\left(\mathrm{V}_{\mathrm{in}}-\mathrm{x}_{2}\right)+\alpha_{2} \mathrm{Lx}_{1}\right)}+\frac{\alpha_{1} \alpha_{2}\left(\mathrm{Rx}_{1}+\mathrm{x}_{2}\right)\left(\mathrm{x}_{2}+\mathrm{V}_{\text {in }}\right)}{\mathrm{R}\left(\alpha_{1} \mathrm{C}\left(\mathrm{V}_{\mathrm{in}}-\mathrm{x}_{2}\right)+\alpha_{2} \mathrm{Lx}_{1}\right)}+\right.\right.\right. \\
& \left.\left.\left.\frac{\alpha_{2} x_{1}\left(\alpha_{1} R C x_{2}+\alpha_{2} L\left(R_{1}+x_{2}\right)\right)}{\operatorname{RC}\left(\alpha_{1} \operatorname{RLC}\left(V_{i n}-x_{2}\right)+\alpha_{2} R L x_{1}\right)}\right):\left(\frac{\alpha_{1} C V_{i n}-\alpha_{1} x_{2} C+\alpha_{2} x_{1} L}{L C}\right)\right) \operatorname{sign}(S)\right]
\end{aligned}
$$

\section{RESEARCH METHOD}

Investigation the response of the buck-boost converter using the proposed controller, some experiments of buck-boost converter are conducted in simulation and it is compared by PID controller using 
ITAE tuning method. Table 1 gives several component parameters that require to be defined such that it is able to validate the proposed method. In order to verify the proposed method in buck-boost converter, it will be compared with PID controller in several scenarios, changing the supply voltage, load, and reference voltage. The constant value of $\alpha \_1, \alpha \_2$, and $\alpha \_3$ are listed in Table 2 . The performance simulation results seen in recovery time ( $\mathrm{t} \_$rec) and voltage deviation.

Table 1. Buck-boost converter parameters

\begin{tabular}{lc}
\hline \multicolumn{1}{c}{ Parameter } & Value \\
\hline Max supply voltage $\left(\mathrm{V}_{\mathrm{i} \text { min }}\right)$ & $15 \mathrm{~V}$ \\
Min supply voltage $\left(\mathrm{V}_{\mathrm{i} \text { max }}\right)$ & $30 \mathrm{~V}$ \\
Output voltage $\left(\mathrm{V}_{\mathrm{o}}\right)$ & $24 \mathrm{~V}$ \\
Resistor $(\mathrm{R})$ & $10 \Omega$ \\
Switching frequency (f) & $20 \mathrm{kHz}$ \\
Inductor $(\mathrm{L})$ & $1000 \mathrm{uH}$ \\
Capacitor $(\mathrm{C})$ & $2200 \mathrm{uF}$ \\
\hline
\end{tabular}

Table 2. Proposed method parameters

\begin{tabular}{cc}
\hline Parameter & Value \\
\hline$\alpha_{1}$ & $1 \times 10^{-8}$ \\
$\alpha_{2}$ & 0.1387 \\
$\alpha_{3}$ & $1 \times 10^{-3}$ \\
\hline
\end{tabular}

\section{RESULTS AND DISCUSSION}

\subsection{Changing input voltage}

For the first investigation, the supply voltage is changed by decreasing and increasing from the initial input voltage, but the desired voltages and load are set in specific value, for instance in PV systems, where the output generated is not constant because it is very dependent on irradiance. The changes made in the experiments are is being as:

$$
v_{\text {in }}(t)=\left\{\begin{array}{r}
7.5, t>0.3 \\
11.25, t>0.3 \\
18.75, t>0.3 \\
22.5, t>0.3 \\
26.25, t>0.3 \\
30, t>0.3
\end{array}\right.
$$

The results for the changing input voltage are shown in Table 3. Simulation of closed loop condition with a changing input voltage (initially $15 \mathrm{~V}$ ) was carried out for 0.7 seconds and when it was 0.3 seconds the supply voltage changed. When the supply voltage decreases, the recovery time for a buck-boost converter with SMC is faster than PID controller as well as when the input voltage increases. Meanwhile, when the input voltage is very large, the recovery time of proposed controller is slower than the PID controller as presented in Figure 2. The largest voltage deviation occurs when the supply voltage set to $7.5 \mathrm{~V}$ with a PID controller which is $3.04 \mathrm{~V}$ and the smallest voltage deviation occurs when the supply voltage changes to $18.75 \mathrm{~V}$ with a SMC which is equal to $0.08 \mathrm{~V}$. Based on Figure 3, it exhibits the voltage deviation proposed controller is lower than PID. The voltage deviation of PID controller is steeper, such that PID controller is not suitable for the system when experiencing changes in input voltage. Figure 4 shows the buck-boost converter with SMC produces a slight overshoot when a disturbance occurs in 0.3 seconds, the output voltage which was initially $-24 \mathrm{~V}$ to $-23.44 \mathrm{~V}$ then the voltage returns to its desired value in 0.3605 seconds. While the output voltage of PID controller indicates overshoot and it is able to follow the reference value in 0.3647 seconds.

Table 3. Experiment results when the input voltage changes

\begin{tabular}{ccccccc}
\hline \multirow{2}{*}{$\mathrm{V}_{\text {in }}(\mathrm{V})$} & \multirow{2}{*}{$\mathrm{V}_{\text {ref }}(\mathrm{V})$} & \multirow{2}{*}{$\mathrm{R}(\Omega)$} & \multicolumn{2}{c}{$\mathrm{SMC}$} & \multicolumn{2}{c}{$\mathrm{PID}$} \\
$\mathrm{t}$ rec & $(\mathrm{s})$ & $\Delta \mathrm{V} \mid(\mathrm{V})$ & $\mathrm{t}_{\text {rec }}(\mathrm{s})$ & $|\Delta \mathrm{V}|(\mathrm{V})$ \\
\hline 7.5 & -24 & 10 & 0.0605 & 0.56 & 0.0647 & 3.04 \\
11.25 & & & 0.0493 & 0.16 & 0.0568 & 1.28 \\
18.75 & & & 0.0404 & 0.08 & 0.0449 & 0.95 \\
22.5 & & & 0.0488 & 0.12 & 0.0458 & 1.73 \\
26.25 & & & 0.0592 & 0.15 & 0.0566 & 2.36 \\
30 & & & 0.0664 & 0.18 & 0.0585 & 2.92 \\
\hline
\end{tabular}




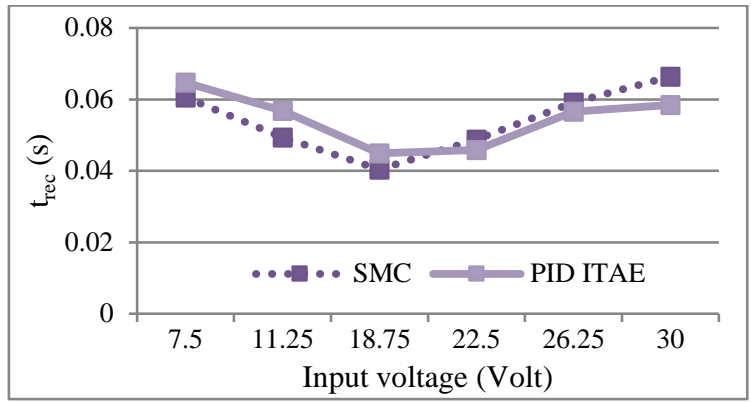

Figure 2. Comparison of $t_{r e c}$ for input voltage change

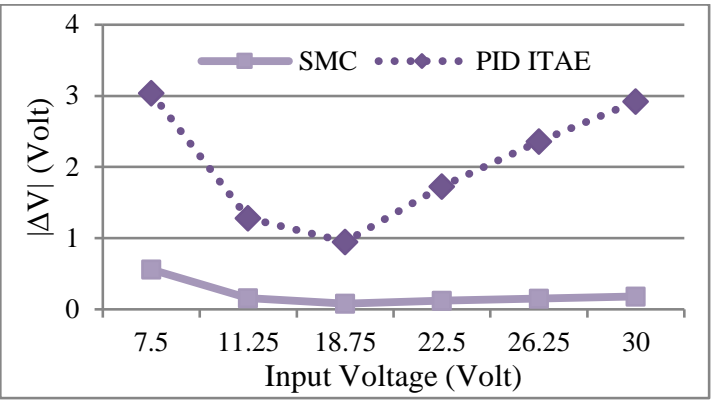

Figure 3. Comparison of $\Delta V$ for input voltage change

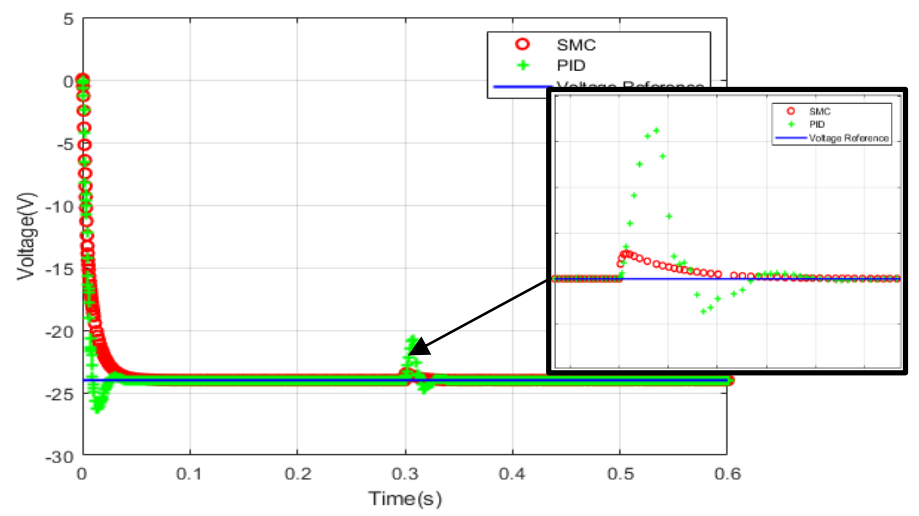

Figure 4. Output voltage when input voltage changes to $7.5 \mathrm{~V}$

\subsection{Changing load}

In the second experiment, the load resistor is set several values. The changed by decreasing and increasing the initial load resistor is conducted gradually, but the supply voltage is set in $15 \mathrm{~V}$ and the reference voltage is in $-24 \mathrm{~V}$. The load changes are defined as:

$$
(t)=\left\{\begin{aligned}
5, t & >0.3 \\
7.5, t & >0.3 \\
12.5, t & >0.3 \\
15, t & >0.3 \\
17.5, t & >0.3 \\
20, t & >0.3
\end{aligned}\right.
$$

The results for this case are stated in Table 4. In the first experiment, the load is reduced by $50 \%$, the time required to return to the desired voltage of the proposed controller is faster than PID controller. This is because when the test occurred after the disturbance, the PID controller experienced oscillations. For further experiments, the recovery time for SMC is slower than PID controller. The longest recovery time occurs when the load changes to $20 \Omega$ on the SMC, which is 0.1108 seconds. For more details, the relationship between load changes and recovery time of the buck-boost converter with proposed controller and PID can be seen in Figure 5. In voltage deviation parameter, SMC produces a smaller deviation compared to the PID controller as shown in Figure 6, furthermore, when the load decreases or increases. The largest voltage deviation occurs when the load changes to $20 \Omega$ on PID controller is $1.22 \mathrm{~V}$ and the smallest voltage deviation occurs when the load changes to $12.5 \Omega$ with an SMC is $0.12 \mathrm{~V}$. When the load decreases, the result of voltage deviation is greater than when the load increases, so the SMC and PID controller is able to overcome this case. From Figure 7, the SMC response has overshoot when a disturbance occurs in 0.3 seconds, the output voltage become $-23.08 \mathrm{~V}$ then it returns to reference value in 0.3377 seconds. In PID controller, the load changes to $5 \Omega$ in 0.3 seconds generates $-22.78 \mathrm{~V}$ then reach the reference value back in 0.3757 seconds and it yields oscillations until the end of the simulation. 
Table 4. Experiment results when the load resistor changes

\begin{tabular}{ccccccc}
\hline \multirow{2}{*}{$\mathrm{V}_{\text {in }}(\mathrm{V})$} & \multirow{2}{*}{$\mathrm{V}_{\text {ref }}(\mathrm{V})$} & \multirow{2}{*}{$\mathrm{R}(\Omega)$} & \multicolumn{2}{c}{$\mathrm{SMC}$} & \multicolumn{2}{c}{ PID } \\
\hline 15 & -24 & 5 & 0.0377 & 0.92 & 0.0757 & 1.22 \\
& & 7.5 & 0.0439 & 0.27 & 0.042 & 0.31 \\
& & 12.5 & 0.0574 & 0.12 & 0.0322 & 0.17 \\
& & 15 & 0.079 & 0.19 & 0.0411 & 0.28 \\
& & 17.5 & 0.0929 & 0.23 & 0.0472 & 0.35 \\
& & 20 & 0.1108 & 0.26 & 0.0604 & 0.41 \\
\hline
\end{tabular}

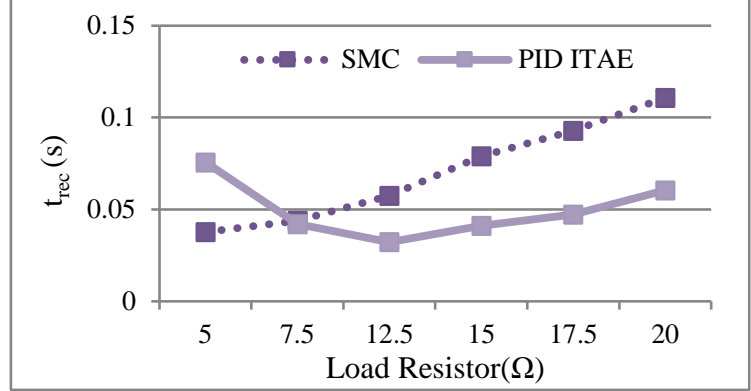

Figure 5. Comparison of $t_{r e c}$ for load resistor change

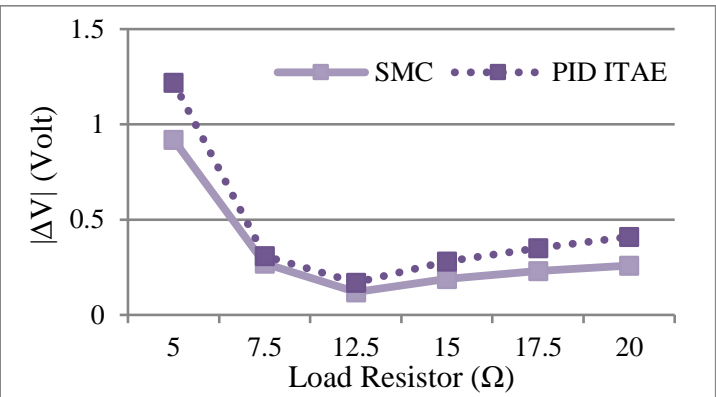

Figure 6. Comparison of $\Delta V$ for load resistor change

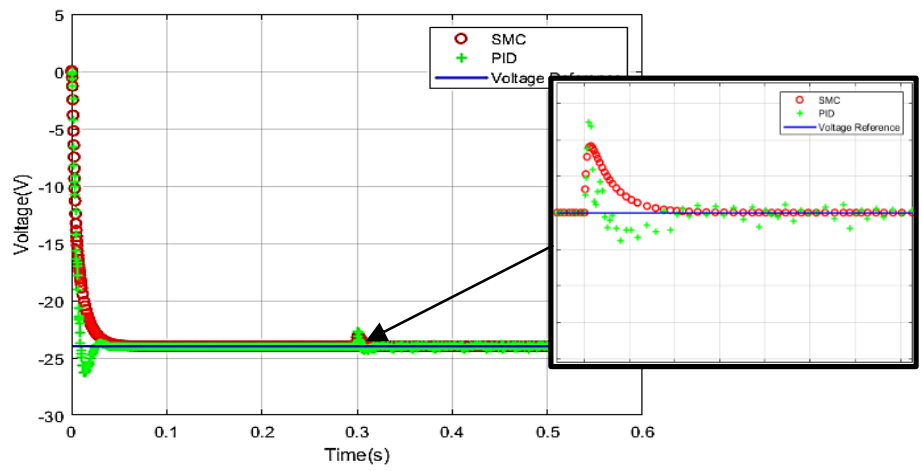

Figure 7. Output voltage when load resistor changes to $5 \Omega$

\subsection{Voltage reference changing}

In last scenario, the reference voltage is changed by decreasing and increasing from the initial reference voltage, but the input voltage and load resistor are kept constant is being as:

$$
v_{\text {ref }}(t)=\left\{\begin{array}{l}
-12, t>0.3 \\
-18, t>0.3 \\
-30, t>0.3 \\
-36, t>0.3 \\
-42, t>0.3 \\
-48, t>0.3
\end{array}\right.
$$

The last experiment results for changing reference voltages are tabulated in Table 5 and indicate the required time to recovery for SMC is slower than the PID controller. Meanwhile, when the reference voltage is increased by $25 \%$, the recovery time of SMC has rapid response than PID controller as shown in Figure 8 . In this scenario there are different results, when the reference voltage increases above $25 \%$, the simulation is not proceeded because the calculated $\mathrm{Kp}, \mathrm{Ki}$, and $\mathrm{Kd}$ parameters are not suitable for changes in this range. The voltage deviation that occurs in the PID controller means that there is always an overshoot at the time of settling time. Figure 9 shows the buck-boost converter with SMC has no overshoot when there is a disturbance at 0.3 seconds and at 0.3971 seconds the output voltage reaches the recent reference, which is $-12 \mathrm{~V}$. The output response of PID controller when the reference voltage changes to $-12 \mathrm{~V}$ in 0.3 seconds generates an output voltage deviation of $-9.961 \mathrm{~V}$ then the voltage follows the reference voltage slowly in 0.3604 seconds. 
Table 5. Experiment results when the voltage reference changes

\begin{tabular}{ccccccc}
\hline \multirow{2}{*}{$\mathrm{V}_{\text {in }}(\mathrm{V})$} & \multirow{2}{*}{$\mathrm{V}_{\text {ref }}(\mathrm{V})$} & \multirow{2}{*}{$\mathrm{R}(\Omega)$} & \multicolumn{2}{c}{$\mathrm{SMC}$} & \multicolumn{2}{c}{$\mathrm{PID}$} \\
& & $\mathrm{t}_{\text {rec }}(\mathrm{s})$ & $\Delta \mathrm{V} \mid(\mathrm{V})$ & $\mathrm{t}_{\text {rec }}(\mathrm{s})$ & $\Delta \mathrm{V} \mid(\mathrm{V})$ \\
\hline \multirow{2}{*}{15} & -12 & \multirow{2}{*}{10} & 0.0971 & 0 & 0.0604 & 2.039 \\
& -18 & & 0.0872 & 0 & 0.0679 & 1.31 \\
& -30 & & 0.0521 & 0 & 0.0714 & 1.8 \\
& -36 & & 0.0799 & 0 & - & - \\
& -42 & & 0.0823 & 0 & - & - \\
& -48 & & 0.0922 & 0 & - & - \\
\hline
\end{tabular}

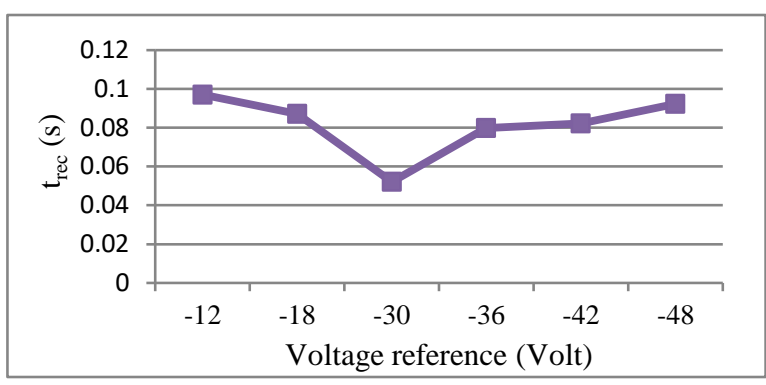

Figure 8. $t_{r e c}$ for voltage reference change in SMC response

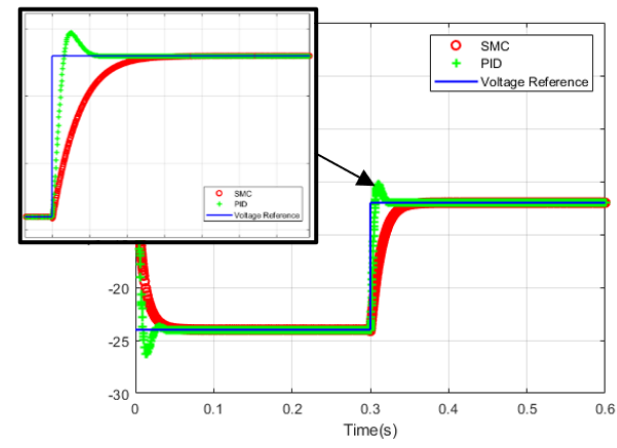

Figure 9. Output voltage when voltage reference changes to $-12 \mathrm{~V}$

\section{CONCLUSION}

The performance results for buck-boost converter using SMC with linear sliding surface and PID controller can be observed by two parameters such as the voltage deviation and recovery time. The given disturbance scenario is conducted in three forms, modifying the supply voltage, varying load, and shifting the reference voltage. The proposed controller when given a disturbance requires a longer recovery time than PID controller. For SMC, the generated voltage deviation is twice smaller than PID controller. However, some conditions, the $\mathrm{Kp}, \mathrm{Ki}$, and $\mathrm{Kd}$ parameters of the PID are not able to continue the simulation due to the infinite calculation. If the voltage deviation is too large, such as that produced by the PID controller, it can damage the existing semiconductor switching components. In addition, SMC is also more adaptive to all changes that occur. This is proven by occurrence of disturbance in the plant, all simulations can run and the resulting output voltage can still return according to the reference.

\section{ACKNOWLEDGEMENTS}

Author thanks to Universitas Brawijaya through Hibah Peneliti Pemula 2021 for providing financial support in this research.

\section{REFERENCES}

[1] F. Blaabjerg, Y. Yang, K. Ma, and X. Wang, "Power electronics - the key technology for renewable energy system integration," 2015 International Conference on Renewable Energy Research and Applications (ICRERA), 2015, pp. 1618-1626, doi: 10.1109/ICRERA.2015.7418680.

[2] F. Blaabjerg and D. M. Ionel, "Renewable energy devices and systems-State-of-the-art technology research and development challenges and future trends," Electr. Power Compon. Syst., vol. 43, no. 12, pp. 1319-1328, 2015, doi: $10.1080 / 15325008.2015 .1062819$

[3] W. Li, X. Xiang, C. Li, W. Li, and X. He, "Interleaved High Step-Up ZVT Converter with Built-In Transformer Voltage Doubler Cell for Distributed PV Generation System," in IEEE Transactions on Power Electronics, vol. 28, no. 1, pp. 300-313, Jan. 2013, doi: 10.1109/TPEL.2012.2199771.

[4] D. Tan and D. Novosel, "Energy challenge, power electronics and systems (PEAS) technology and grid modernization," in CPSS Transactions on Power Electronics and Applications, vol. 2, no. 1, pp. 3-11, 2017, doi: 10.24295/CPSSTPEA.2017.00002.

[5] N. Tiwari and A. N. Tiwari, "Performance Analysis of Unidirectional and Bidirectional Buck-Boost Converter Using PID Controller," 2018 2nd International Conference on Electronics, Materials Engineering \& Nano-Technology (IEMENTech), 2018, pp. 1-6, doi: 10.1109/IEMENTECH.2018.8465229.

[6] F. Nejabatkhah, Y. W. Li, A. B. Nassif, and T. Kang, "Optimal design and operation of a remote hybrid microgrid," in CPSS Transactions on Power Electronics and Applications, vol. 3, no. 1, pp. 3-13, March 2018, doi: 10.24295/CPSSTPEA.2018.00001.

[7] D. Divan and P. Kandula, "Distributed power electronics: An enabler for the future grid," CPSS Transactions on Power Electronics and Applications, vol. 1, no. 1, pp. 57-65, Dec. 2016, doi: 10.24295/CPSSTPEA.2016.00006. 
[8] P. Li, C. Zhang, Z. Kan, and B. Ben, “An integrated Buck-Boost CLLC bidirectional DC converter with high gain and soft switching," Proceedings of the CSEE, vol. 38, no. 11, pp. 3295-3305, 2018, doi: 10.13334/j.0258-8013.pcsee.170494.

[9] Min-Sang Seong, Seung-Bok Choi, and Kum-Gil Sung. "Control Strategies for Vehicle Suspension System Featuring Magnetorheological (MR) Damper," Vibration Analysis and Control: New Trends and Developments; InTech: London, UK, pp. 97-114, 2011, doi: 10.5772/24556.

[10] W. Lin, X. Guo, and C. Huang, "Bi-directional DC-DC converters with large conversion ratio based on improved one-cycle control," Proceedings of the CSEE, vol. 32, no. 21, pp. 31-37, 2012.

[11] H. Guldemir, "Modeling and Sliding Mode Control of DC-DC Buck-Boost Converter," 6th International Advanced Technologies Symposium (IATS'11). Elazığ, Turki, vol. 4, pp. 475-480, May 2011.

[12] R. K. Subroto, L. Ardhenta, and S. N. Sari, "Lyapunov based Estimator for Buck Converter," 2018 Electrical Power, Electronics, Communications, Controls and Informatics Seminar (EECCIS), 2018, pp. 287-292, doi: 10.1109/EECCIS.2018.8692911.

[13] L. Ardhenta, P. Kuswiradyo, and R. K. Subroto, "Model direct adaptive control of buck converter by using MRAC", International Journal of Innovative Technology and Exploring Engineering, vol. 8, no. 12, pp. 1108-1112, 2019, doi: 10.11591/ijpeds.v11.i2.pp851-858.

[14] G. Abbas, M. A. Samad, J. Gu, M. U. Asad, and U. Farooq, "Set-point tracking of a dc-dc boost converter through optimized PID controllers," 2016 IEEE Canadian Conference on Electrical and Computer Engineering (CCECE), 2016, pp. 1-5, doi: 10.1109/CCECE.2016.7726841.

[15] A. E. A. Awouda and R. B. Mamat, "Refine PID tuning rule using ITAE criteria," 2010 The 2nd International Conference on Computer and Automation Engineering (ICCAE), 2010, pp. 171-176, doi: 10.1109/ICCAE.2010.5451484.

[16] R. Caceres, R. Rojas, and O. Camacho, "Robust PID control of a buck-boost DC-AC converter," INTELEC. Twenty-Second International Telecommunications Energy Conference (Cat. No.00CH37131), 2000, pp. 180-185, doi: 10.1109/INTLEC.2000.884248.

[17] L. Ardhenta, M. R. Ansyari, R. K. Subroto, and R. N. Hasanah, "DC Voltage Regulator using Buck-Boost Converter Based PIDFuzzy Control," 2020 10th Electrical Power, Electronics, Communications, Controls and Informatics Seminar (EECCIS), 2020, pp. 117-121, doi: 10.1109/EECCIS49483.2020.9263425.

[18] O. Ibrahim, N. Z. Yahaya, and N. Saad, "Comparative studies of PID controller tuning methods on a DC-DC boost converter," 2016 6th International Conference on Intelligent and Advanced Systems (ICIAS), 2016, pp. 1-5, doi: 10.1109/ICIAS.2016.7824044.

[19] N. G. M. Thao, M. T. Dat, T. C. Binh, and N. H. Phuc, "PID-fuzzy logic hybrid controller for grid-connected photovoltaic inverters," International Forum on Strategic Technology 2010, 2010, pp. 140-144, doi: 10.1109/IFOST.2010.5668024.

[20] L. Martinez-Salamero, A. Cid-Pastor, R. Giral, J. Calvente, and V. Utkin, "Why is sliding mode control methodology needed for power converters?," Proceedings of 14th International Power Electronics and Motion Control Conference EPE-PEMC 2010, 2010, pp. S9-25-S9-31, doi: 10.1109/EPEPEMC.2010.5606524.

[21] D.W. Hart, "Power Electronics," Tata McGraw-Hill Education, 2011.

[22] R. H. G. Tan and L. Y. H. Hoo, "DC-DC converter modeling and simulation using state space approach," 2015 IEEE Conference on Energy Conversion (CENCON), 2015, pp. 42-47, doi: 10.1109/CENCON.2015.7409511.

[23] J. Y. Hung, W. Gao, and J. C. Hung, "Variable structure control: a survey," in IEEE Transactions on Industrial Electronics, vol. 40, no. 1, pp. 2-22, Feb. 1993, doi: 10.1109/41.184817.

[24] J. J. E. Slotine and W. Li, "Applied Nonlinear Control," NJ: Prentice Hall, 1991.

[25] C. C. Soon, R. Ghazali, H. I. Jaafar, and S. Y. S. Hussiend, "Sliding Mode Controller Design with Optimized PID Sliding Surface using Particle Swarm Algorithm,” Procedia Computer Science, vol. 105, pp. 235-239, 2017, doi: 10.1016/j.procs.2017.01.216.

\section{BIOGRAPHIES OF AUTHORS}

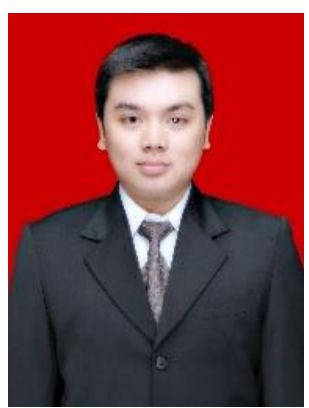

Lunde Ardhenta (iD SI SC P received the M.S. degree in Department of Electrical Engineering, National ChiaYi University, Taiwan in 2015. He complete Bachelor degree in Department of Electrical Engineering, Universitas Brawijaya, Indonesia in 2011. He is currently a junior lecturer at Department of Electrical Engineering, Universitas Brawijaya, Indonesia. His research interests include renewable energy applications, linear control and digitalized control techniques, and power electronics. He can be contact at email: lunde.ardhenta@ub.ac.id.

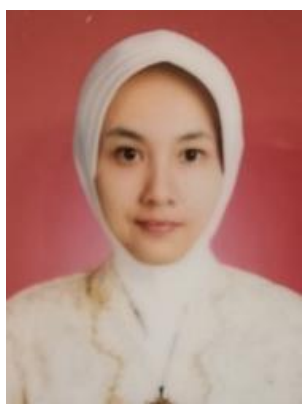

Tri Nurwati (ID S SC P was graduated in electrical engineering from Universitas Brawijaya-Indonesia, got her postgraduate master degree in electrical engineering from Institut Teknologi Sepuluh Nopember-Indonesia, and got her doctoral degree in electrical engineering from Université de Picardie Jules Verne. She joined the Electrical Engineering department at Universitas Brawijaya, Indonesia in 2008. Her research interests include renewable energy, control engineering, and power electronics. She can be contact at email: trinurti@ub.ac.id. 